\title{
Arquitet@s negr@s \\ e a história: \\ Georgia Brown, São Paulo Metropolitana e seus fantasmas
}

\author{
Juan Casemiro, \\ José Tavares Correia de Lira*
}

\begin{abstract}
Resumo $O$ presente artigo tem como propósito discutir o silêncio da historiografia de arquitetura em torno da atuação de arquitetos e urbanistas negros ou mulheres no Brasil. Tomando como guia a trajetória da arquiteta negra estadunidense Georgia Louise Harris Brown, trata-se não somente de observar como sua atuação se cruza com sua condição de raça, gênero e nacionalidade, mas como o seu recrutamento por distintas empresas de engenharia e construção permitiu-lhe intervir de modo duplamente sutil no processo de metropolização: enquanto peça invisível de uma complexa engrenagem produtiva de conversão da grande São Paulo em um dos mais dinâmicos territórios industriais do país, e como modo de compreender a construção da cidade para além do campo especializado do planejamento urbano.
\end{abstract}

Palavras-chave: raça, industrialização, arquitetura.

\section{Architect@s negr@s e la historia: Georgia Brown, la metropolización de São Paulo e sus fan- tasmas}

\begin{abstract}
Resumen Este artículo discute el silencio de la historiografía arquitectónica sobre la actuación de los arquitectos y urbanistas negros o mujeres en Brasil. Tomando como guía la trayectoria de la arquitecta negra estadounidense Georgia Louise Harris Brown, trata-se de observar cómo su trabajo, junto a diferentes empresas de ingeniería y construcción, se cruza con su condición de raza, género y nacionalidade, mientras intervienen de forma doblemente sutil en el proceso de metropolización: como una pieza invisible de un complejo engranaje productivo para la conversión del Gran São Paulo en uno de los territorios industriales más dinámicos del país, y como forma de comprensión de la construcción de la ciudad para além del referente especializado del urbanismo.
\end{abstract}

Palabras clave: raza, industrialización, arquitectura.

\section{Black Architects and history: Georgia Brown, São Paulo's metropolization and its ghosts}

\begin{abstract}
This article aims at discussing the silence of architectural historiography around the work of black or women architects and urban planners in Brazil. Taking the professional itinerary of the U.S. black architect Georgia Louise Harris Brown as a guideline, we intend to address her work by both taking into consideration her conditions of race, gender and nationality; and as a way of intervening in the local process of metropolization in two subtle ways: as an invisible part of a more complex productive machine in the conversion of Greater São Paulo into one of the most dynamic industrial areas in the country, and as a way of understanding the building of the city beyond the specialized field of urban planning.
\end{abstract}

Keywords: race, industrialization, architecture. 
Assim, a vida dos vaga-lumes parecerá estranha e inquietante, como se fosse feita da matéria sobrevivente - luminescente, mas pálida e fraca, muitas vezes esverdeada - dos fantasmas. Fogos enfraquecidos ou almas errantes. Georges Didi- Huberman ${ }^{1}$

0

fantasma ou sua aparição são uma forma pela qual o que está perdido, invisível, ou aparentemente oculto aos nossos olhos dá-se a conhecer ou se faz visível (GORDON, 1997). Há dois tipos de aparições: as literais, se é que podemos dizer assim, que se referem ao regresso dos mortos sob qualquer forma perceptível aos vivos, e as metafóricas, que dizem respeito aos seres humanos que mais cedo ou mais tarde retornam como fantasmas, seja como sobrevivências, revivescências, vestígios de alguns de seus traços fundamentais, seja como fantasmas a assombrar as sociedades que historicamente os invisibilizaram. Estes últimos são denominados "fantasmas vivos" e nesta categoria podem incluir-se imigrantes, trabalhadores domésticos, negros, mulheres, homossexuais e tantos outros alvos de invisibilidade social (PEEREN, 2014). Este ensaio irá se ater a alguns destes "fantasmas vivos": arquitetos negros que atuaram no Brasil e cuja atuação no urbanismo, na arquitetura e na produção da cidade permanece desconhecida.

A ideia de relacionar estes personagens negligenciados a fantasmagorias, como o fez Beatriz Colomina (2010) acerca das arquitetas invisíveis na história da arquitetura moderna, é motivada não tanto pelo interesse pelo que ainda está oculto mas, sobretudo pelas implicações que a memória e o trauma histórico a respeito dos negros em geral continuam exercendo nas políticas do presente. A fantasmagoria então se coloca como categoria central no desvendamento dessas (outras) histórias, de vozes omitidas, questionando relações entre passado, presente e futuro na historiografia de arquitetura. Podemos ainda pensá-la como estratégia de análise do passado arquitetônico que se recusa a ser encarado, absolvido, superado (SOLOMON-GODEAU, 2006). O fantasma, através de sua aparição opera como instrumento de eterno retorno no presente, tanto de memórias não desejáveis, propositalmente esquecidas, como de formas, traços, vestígios ancestrais, às vezes de coisas minúsculas, supérfluas, banais, que tenazmente e tenuemente permanece do passado (DIDI-HUBERMAN, 2013: 47). E assombram todos aqueles que insistem em perpetuar uma história única, eurocêntrica, branca, masculina, heterossexual.

O que nos interessa aqui é tratar destas outras histórias de profissionais negros, que dificilmente se encontram em manuais de história, dicionários, enciclopédias, monografias e catálogos de arquitetura e urbanismo. Há uma lacuna no feixe historiográfico, e que pelo menos até meados dos anos 1990, evidencia um mecanismo não só de apagamento, como de esquecimento tanto em relação à sua contribuição, quanto, sobretudo, à sua condição

* Juan Casemiro é Arquiteto e Urbanista, Mestrando pela Faculdade de Arquitetura e Urbanismo da Universidade de São Paulo ORCID <https://orcid.org/00000003-4061-6638>. José Tavares Correia de Lira é Arquiteto e Urbanista, Professor da Faculdade de Arquitetura e Urbanismo da Universidade de São Paulo, ORCID <https://orcid.org/00000003-2770-9186>. e handicap étnicos. A despeito da diversidade de perspectivas assumidas pela bibliografia especializada, poucos foram os textos que se detiveram sobre as trajetórias individuais destes personagens, especialmente os profissionais negros, em geral desconsiderados. Eles eram aqueles que faziam a casa ou a cidade funcionar, para utilizar a expressão de Lucio Costa ${ }^{2}$, como figuras responsáveis na sociedade escravocrata ora pelo trabalho doméstico, ora por serviços urbanos essenciais, como o transporte de pessoas e coisas, a limpeza de ruas e calçadas, a destinação do lixo e dejetos das famílias ${ }^{3}$. Ele também poderia ser figurado como trabalhador manual na história das construções, por vezes visto, inclusive, como produtor de valores arquitetônicos, tidos como vernaculares, populares 
1 DIDI-HUBERMAN, G. Sobrevivência dos vaga-lumes. Belo Horizonte: Editora UFMG, 2011, p. 13-14.

2 COSTA, Lúcio. "Depoimento de um arquiteto carioca". In: Centro dos Estudantes Universitários de Arquitetura. Lúcio Costa: sobre arquitetura. Porto Alegre: UFRGS, 1962.

3 Ver FREYRE, Gilberto. Sobrados e Mucambos. São Paulo: Nacional, 1936; STRAUMANN, Patrick; ALENCASTRO, Luis Felipe de (orgs. ). Rio de Janeiro: cidade mestiça. São Paulo: Cia. Das Letras, 2001; SLENES, Robert Wayne. Na senzala, uma flor. $2^{a}$ ed. corrigida. Campinas: Editora da Unicamp, 2011; FARIAS, Juliano Barreto. Cidades negras. São Paulo: Alameda, 2006.

4 FREYRE, Gilberto. Mucambos do Nordeste. Rio de Janeiro: Sphan/ Ministério da Educação e Saúde, 1937. Ver ainda COSTA, Lucio. "Documentação necessária". In: Revista do Patrimônio Histórico e Artístico Nacional, n. 1, Rio de Janeiro, 1937; CARDOZO, Joaquim. "Arquitetura Popular no Brasil". Módulo, n.5, p. 20-23, set. 1956; BARDI, Lina Bo. "Amazonas, o povo arquiteto". Habitat, São Paulo, n. 1, p. 68-71, out/dez 1950; Idem, "Construir com simplicidade". Habitat, São Paulo, n. 9, p. 15, out/Nov-dez 1952.

5"Influência do negro na arquitetura brasileira", Acervo Centro de Documentação e Memória (Cedem) da UNESP. Disponível em: $<$ https://arquitetoehistoriasdetijolos.files.wordpress.com/2016/12/ influencia-do-negro-na-arquitetura-brasileira.pdf $>$. Acesso em 25 Jul 2020.

6 WEIMER, Günter. Inter-Relações Afro-Brasileiras na Arquitetura. Porto Alegre, Rio Grande do Sul: EDIPUCRS, 2014; Idem, Arquitetura Popular Brasileira. São Paulo: Martins Fontes, 2005.

7 CUNHA, Marianno C. da. Da senzala ao sobrado: arquitetura brasileira na Nigéria e na República do Benim, São Paulo, Nobel/ Edusp, 1985. ou tradicionais, especialmente na construção de suas próprias moradias, como no estudo seminal de Gilberto Freyre sobre os Mucambos do Nordeste, de 1937, no próprio Lúcio Costa, de Documentação Necessária, ou em estudos ulteriores sobre a arquitetura de favelas e palafitas. ${ }^{4}$ Por fim, uma de suas figurações fundamentais seriam aquelas dos negros como moradores da cidade, em sua concentração ou segregação sócio-espacial, em seus territórios próprios, em suas relações com outros grupos, desde estudos clássicos como o de Donald Pierson sobre a Bahia ou de Florestan Fernandes sobre São Paulo, até trabalhos mais recentes, de variadas orientações teóricas.

Entre as múltiplas e recorrentes lacunas bibliográficas, especialmente no campo da arquitetura e urbanismo, umas das grandes ausências é, justamente, em torno do trabalho e mesmo da existência no país de arquitetos e urbanistas negros. Mesmo o estudo sistemático acerca da "Influência do negro na arquitetura brasileira", promovido pelo Instituto Brasileiro de Estudos Africanistas (IBEA) e apresentado no I Congresso de Culturas Negras da América em 1977, reincide no recorrente anonimato da contribuição ou "influência" dos negros na arquitetura. Há nele, por certo, vários aspectos de inovação, inclusive por ter sido conduzido por arquitetos, alguns dos quais negros e mulheres, e desenvolvido em um contexto de afirmação africanista. Nem por isso o estudo viria a enfatizar a atuação dos negros como profissionais de arquitetura e urbanismo, detendo-se na arquitetura construída pelas camadas populares. Ainda assim, viria a propor uma agenda de investigação - envolvendo temas como a arquitetura do quilombo, a arquitetura das irmandades religiosas negras, métodos e técnicas construtivas empregadas, a influência africana na organização físico-espacial ${ }^{5}$ - que ainda hoje vem ressoando em iniciativas que ora tematizam as inter-relações entre a África e o Brasil na arquitetura, ora a presença afro-brasileira na arquitetura popular ${ }^{6}$.

De fato, as únicas biografias de profissionais negros que conseguimos mapear são as de Joaquim Pinto de Oliveira (1721- 1781), conhecido como Tebas; e a de Antônio Francisco Lisboa, o Aleijadinho (1738-1814), ambos, aliás, atuantes numa sociedade colonial escravocrata, em que distinções entre brancos e negros forneciam os elementos chave da divisão do trabalho, e, claro, a profissão e a formação do arquiteto ainda não estavam estabelecidas. Um estudo pioneiro em torno da atuação de ex-escravizados no Brasil ao retornarem aos atuais Benin e Nigéria, de Mariano Carneiro da Cunha, observou porém a importância desses grupos na formação de uma burguesia nascente em diversas cidades africanas a partir da segunda metade do XIX, e o papel inovador dos construtores brasileiros de ascendência iorubá na definição de estilos construtivos, plantas, materiais e técnicas na África. Homens como Balthazar dos Reis, Francisco Nobre, Lázaro Borges da Silva, Joaquim Devodê Branco, entre dezenas de mestres de obras, pedreiros, carpinteiros, marceneiros libertos, que uma vez na África assumiriam encargos como igrejas, mesquitas, lojas, armazéns, residências etc. ${ }^{7}$

O fato é que a produção arquitetônica desses homens negros parece desaparecer à medida que avançamos no longo do século XX. Tudo se passa, como se a consolidação ulterior do sistema arquitetônico, com a regulamentação da profissão e o florescimento de escolas de arquitetura independentes a partir do segundo terço do século XX, viesse a reforçar a exclusão desses profissionais. Como se a própria afirmação da profissão produzisse novas séries de apagamentos no âmbito da produção, tornando ainda mais improváveis não só o reconhecimento autoral, como a própria atuação de artesãos, artífices, mestres de obras, práticos licenciados, muitos dos quais negros e pardos, 
8 Nem os órgãos de regulamentação (CREA, CAU/BR), nem associações como o IAB, a ABEA ou a ASBEA possuem dados relativos à origem étnica dos profissionais, escritórios e estudantes registrados.

9 Roderick O'neal--leader among Negro architects. The lowa Alumni Review, Vol VII, 5 de Ago. 1954.

10 O'Neal One Of Youngest Architects In Country. The Pittsburgh Courier, 30 de Jan. 1954.

11 The Pittsburgh Courier, 3 de Dez 1949.

9 Roderick O'neal--leader among Negro architects. The lowa Alumni Review, Vol VII, 5 de Ago. 1954.

10 O'Neal One Of Youngest Architects In Country. The Pittsburgh Courier, 30 de Jan. 1954.

11 The Pittsburgh Courier, 3 de Dez 1949. doravante interditados, desconsiderados, silenciados. Nem mesmo hoje, quando as denúncias acerca desse apagamento são bem mais sonoras, é possível encontrarmos dados mais claros acerca das disparidades de raça no campo da arquitetura e do urbanismo. ${ }^{8}$ A ausência de dados e estatísticas substantivos a respeito de raça é não só expressivo dos obstáculos à superação das desigualdades e invisibilidades históricas no meio arquitetônico e urbanístico, como um entrave ao entendimento de suas transformações contemporâneas nesse âmbito.

Assim, a despeito da promoção recente do debate racial no país, do afluxo de políticas afirmativas e mesmo das conquistas dos afrodescendentes no campo dos direitos, do trabalho e da educação, as grandes coordenadas de estudo de sua presença no campo da arquitetura e urbanismo não parecem ter sido significativamente alteradas. A fantasmagoria instaura-se aqui, portanto, não somente como reiteração do fetichismo implícito à divisão do trabalho, mas como forma de alcançar camadas condenadas à opacidade na história. IE as limitações bibliográficas não são exclusivas ao Brasil. Nos EUA, em 2004, elas motivariam a organização de um dicionário biográfico de arquitetos afro-americanos, o African American Architects: A Biographical Dictionary, 1865-1945, a cargo de Dreck Spurlock Wilson (WILSON, 2004), que viria a incluir mais de uma centena de profissionais. Nele, vale destacar, uma das poucas mulheres incluídas foi Georgia Louise Harris Brown (1918-1999), que curiosamente trabalhou no Brasil a maior parte de sua vida, sempre anonimamente.

\section{Uma arquiteta negra na metropolização de São Paulo}

Considerada a segunda profissional negra licenciada nos Estados Unidos, Georgia Louise atuou em São Paulo na segunda metade do século XX. Ao final dos anos 1930, estudou na Universidade de Washburn e no Instituto de Tecnologia de Illinois, formando-se arquiteta pela Universidade de Kansas em 1944. Começou sua carreira nos EUA em 1945, colaborando no escritório de Kenneth Roderick O'Neal (19081989), em Chicago até 1949. Uma matéria publicada na revista lowa Alumni Review, ${ }^{9}$ chamou-o de "líder entre os arquitetos negros". Outro artigo no The Pittsburgh Courier ${ }^{10}$, afirma que O'Neal era "um dos mais jovens e bem-sucedidos arquitetos e engenheiros negros do país". Foi em seu escritório que Louise pode conviver com outros dois importantes arquitetos negros: Beverly Loraine Greene, que é considerada a primeira arquiteta negra licenciada dos EUA, e John W. Moutoussamy. (figura 1)

Em 1949, ao obter sua licença profissional, transfere-se para a Frank J. Kornacker \& Associates, uma empresa especializada em engenharia civil comandada pelo engenheiro desde 1945. Louise era a única mulher atuando no escritório nesta época, e foi ali que se envolveu em projetos de cálculo estrutural de alguns edifícios icônicos de Mies Van der Rohe na cidade, como os edifícios na Lakeshore Drive. Ela descreve este momento como um dos mais emocionantes de sua carreira ${ }^{11}$. Segundo Washington (2004), ela estava bem ciente de que nos Estados Unidos as oportunidades de progresso eram limitadas por sua raça e é aí que teria reconhecido no Brasil a oportunidade de praticar arquitetura livre das rígidas fronteiras raciais nos Estados Unidos dos anos 1950. Seduzida pelo mito da democracia racial e pelo cenário arquitetônico, decide se mudar para São Paulo em 1953 (Washington, 2004). Pelo fato de ser estrangeira, não consegue abrir um escritório próprio, o que só irá ocorrer quase duas décadas depois, quando obtém sua licença profissional junto ao CREA/SP. 


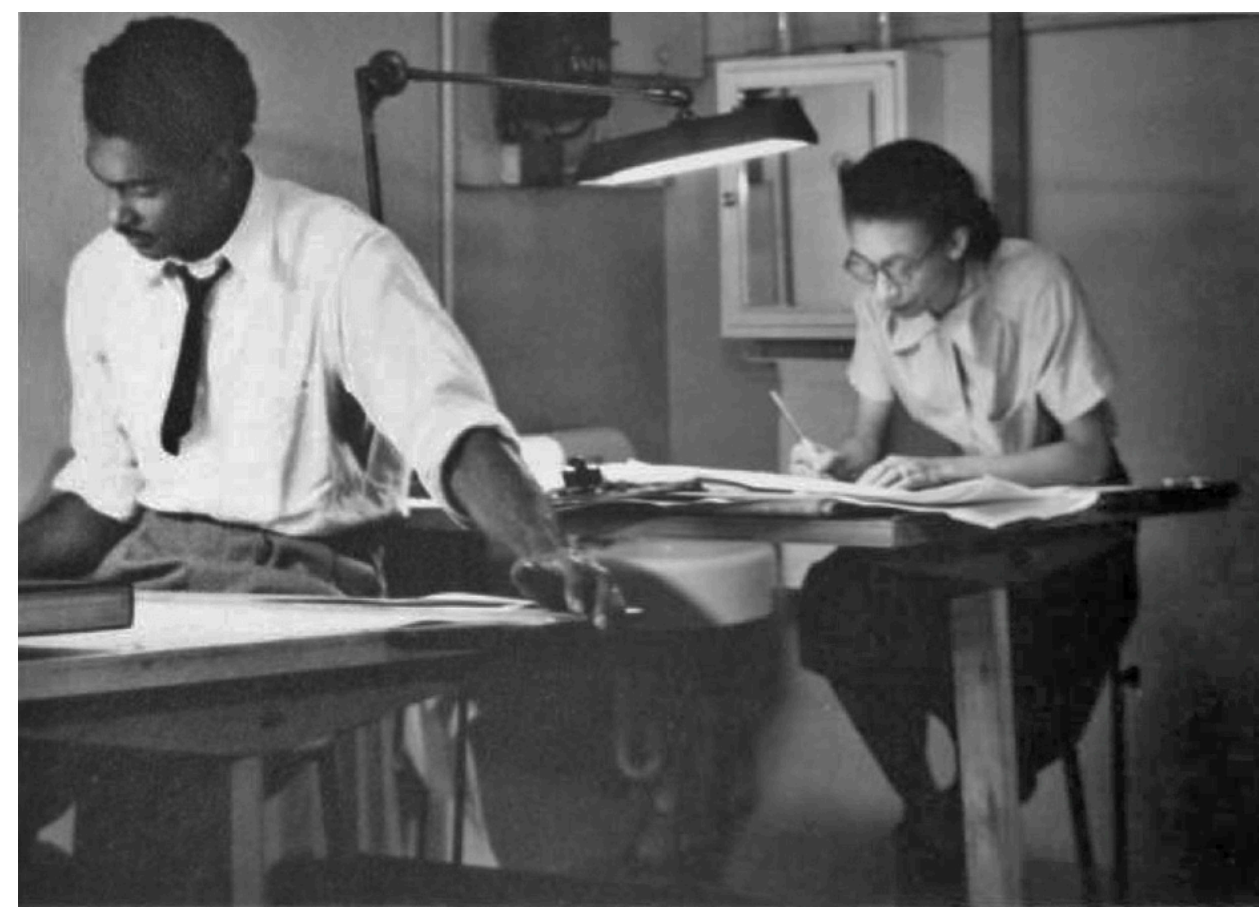

Figura 1: Georgia Louise Harris Brown e John W. Moutoussamy trabalhando no escritório de Kenneth Roderick O'neal em 1948. Fonte: Acervo Brian O'Neal.
Ela começa a trabalhar na empresa do arquiteto americano Charles Bosworth em 1954. Bosworth também era estadunidense e mudara-se para o Brasil em 1947, incentivado pela proposta do designer nova iorquino Raymond Loewy de abrirem juntos um escritório em São Paulo. Entre os primeiros trabalhos da firma estão a sede do American Club do Rio, residências na Gávea e outras construções em São Paulo. Nos anos seguintes, Bosworth se tornou a figura central em duas grandes empreiteiras, com escritórios e projetos que se estendiam de São Paulo, Recife e Porto Alegre a Buenos Aires. Essas empresas executaram mais de cem projetos industriais no Brasil. Os clientes incluíam Ericsson, Pfizer, Merck Sharp \& Dohme, Willys Overland do Brasil e também Ford, General Motors, Brasmotor do Brasil, White Martins, Union Carbide, a sede da Xerox no Rio de Janeiro entre tantas outras (LEFFINGWELL, 2003). Alguns deles tiveram ampla repercussão e em 1961 levaram a revista L'Architecture d'Aujourd'hui a publicar, em seu número 95, dedicado à arquitetura industrial, os projetos para as fábricas Pfizer, Ford (1957-63), Willis Overland (1960) e Lion do Brasil (1957), os dois primeiros, além da sede do National City Bank em São Paulo, contando com a participação de Georgia. Ela também trabalhou em outras construtoras, como a Escandia, responsável por alguns dos pavilhões montados durante as comemorações do IV Centenário da Cidade de São Paulo, no Parque Ibirapuera; e a RACZ, onde desenvolveu o projeto da fábrica da KODAK, em São José dos Campos (1969-71/1975-76); o escritório empresarial da KODAK em São Paulo (sem data); Fundada em 1941 pelos italianos Daniele Calabi e Silvio Segre, com o nome de Construtora Moderna, a RACZ foi adquirida em 1952 pelo engenheiro húngaro Joszef Racz, que a eles se associara quatro anos antes, assumindo a nova denominação (NASSIF, 2019; MELLO, 2012). O grande salto da empresa se deu em 1956, com o contrato para construção de uma fábrica da Volkswagem, em São Bernardo do Campo. A partir deste projeto, a Racz viria a responder por outras 
12 Ver processo R1274/69 CX 722. CAU/SP.

13 Coleção Rino Levi, junto à biblioteca da FAU/USP. O documento específico foi gentilmente compartilhado com os autores pela Profa. Dra. Mônica Junqueira de Camargo. obras grandes, como o Conjunto Industrial da Companhia Franco Brasileira de Anilinas (CFBA) em Jacareí, também em 1956; a Fábrica de equipamentos Clark Mac S/A, em Valinhos, em 1958; e em 1969 o Parque Industrial da KODAK, em São José dos Campos, assinado por Georgia. Em 1978, a arquiteta ainda projetaria dois postos de atendimento do Instituto Nacional de Previdência Social em Heliópolis e no Ipiranga, em São Paulo.

Alguns anos depois de finalmente adquirir sua licença profissional junto ao CREASSP ${ }^{12}$, em meados dos anos 1970 ela funda sua própria empresa, a GRYPHUS Arquitetura, e então pode finalmente assinar seus projetos, trabalhando com alguns poucos colaboradores. A partir de então ela começará a atuar independentemente destes grandes escritórios, assumindo projetos de casas, pequenas indústrias, galpões e laboratórios. A inflexão profissional parece denotar que seu afastamento do meio dominantemente masculino retira-Ihe a possibilidade de envolver-se com grandes empreendimentos, de forma que, ao abrir seu próprio escritório, ela acaba recolhendo-se a uma encomenda mais modesta. Ensaiando, sobretudo, uma poética da domesticidade, das micropolíticas do lar, no desenho de mobiliário e objetos, universo da profissão frequentemente relegado às mulheres. Depois de quase quatro décadas atuando em São Paulo, em 1993, após ser diagnosticada com mal de Alzheimer, ela retorna aos EUA, onde falece em 21 de Setembro de 1999.

Embora sua escolha pelo Brasil, por ser um país supostamente sem tensões raciais, pode parecer ingênua, ela se estabelece em São Paulo num momento de grande desenvolvimento da cidade, da indústria e da construção civil. Sua experiência em obras de grande porte nos EUA, assim como elos eventuais com a rede de empresários norte-americanos atuantes na urbanização da cidade, provavelmente contribuíram para que ela se envolvesse de imediato no desenvolvimento de projetos de grande porte, como plantas industriais. Não custa lembrar que se tratava de um momento de enorme expansão dos investimentos norte-americanos fora do país, em grande parte na América Latina ( $37 \%$ do total dos investimentos privados no exterior), o que vinha incentivando a instalação de empresas, empresários e profissionais, e não menos de modelos tecnológicos daquele país no Brasil (CODY, 2003: 123-128; 141-144).

A ideia de emigrar é bem anterior à efetiva transferência da arquiteta para São Paulo. Em uma carta enviada em novembro de 1949 para o arquiteto Rino Levi, ela pede recomendações de trabalho e menciona suas experiências profissionais: projetos de construção, plantas em geral, bem como trabalhos mais minuciosos; e cálculos ligados aos vários métodos de construção, no campo da arquitetura residencial e comercial. $\mathrm{O}$ arquiteto então lhe responde que vindo a São Paulo ela certamente iria encontrar emprego. Importante mencionar que nesta carta ela também menciona sua intenção de vir com a família, inclusive com o marido, de quem se divorciaria em 1952. Após a separação, ela decide se mudar sozinha no ano seguinte para São Paulo, deixando seus dois filhos provisoriamente com os avós em Topeka. ${ }^{13}$ Ela encontra um cenário de metropolização em ebulição, marcado pela industrialização, impulsionado sobretudo pelas políticas desenvolvimentistas do país, que acentuavam ainda mais a concentração industrial na cidade e seu entorno. O processo tomou impulso no governo de Juscelino Kubitschek, que combinou a política de intervencionismo estatal na economia e incentivo à indústria nacional com a atração de grande número de empresas estrangeiras para o Brasil, principalmente no ramo da indústria automobilística, naval, mineradora, 
14 SAGMACS/ Comissão de Pesquisa Urbana da Prefeitura de São Paulo. Estrutura Urbana de Aglomeração Paulista, São Paulo, SAGMACS, 1958. Cf. CESTARO, Lucas. Urbanismo e humanismo: a SAGMACS e o estudo da 'Estrutura Urbana da Aglomeração Paulistana'. Dissertação de Mestrado em Arquitetura e Urbanismo. IAU-USP, São Carlos-SP, 2008. química e mecânica, por intermédio de subsídios, como doação de terrenos, isenção de impostos e empréstimos estrangeiros (RIBEIRO, 1995).

Não por acaso, nas décadas de 1950 e 1960, o processo de aglomeração metropolitana em São Paulo ganha forma. O estudo conduzido pela Sagmacs em 1958 sobre a "Estrutura urbana da aglomeração paulistana" não é apenas pioneiro na incorporação de variáveis históricas e sociológicas no âmbito do planejamento urbano, mas a destacarem o fato de que as transformações resultantes do ciclo de industrialização em curso exigia o entendimento da cidade para além de seus limites, de modo a pensá-la na escala da Great São Paulo, envolvendo municípios vizinhos como Santo André, São Bernardo, São Caetano e Guarulhos. ${ }^{14}$ Municípios localizados no entorno da capital paulista, notadamente no ABCD, mas também em Guarulhos, Osasco e em direção ao Vale do Paraíba se constituíram como verdadeiros polos dessa fase de industrialização do país. Em primeiro lugar, por apresentarem geograficamente uma proximidade com a cidade de São Paulo e o Porto de Santos, e, em segundo lugar, pela existência de terras planas e grandes áreas disponíveis de baixo valor imobiliário, caracterizando-se também por isso como acessíveis à moradia do novo proletariado industrial em formação.

Um dos fatores que permitiram a localização dessa nova geração de indústrias nos municípios vizinhos a capital foi justamente a consolidação de uma grande rede de rodovias pavimentadas, ao longo das quais elas tenderiam a se instalar. É seguindo estas novas coordenadas que, entre os anos 1950 e 1960, que se desenrola o vertiginoso crescimento e diversificação do parque industrial paulista, já bastante significativo no período (FRANCISCO, 2000).

Estes atributos somados aos incentivos governamentais fizeram com que empresas de grande porte e multinacionais, se instalassem nestas cidades. No final dos anos 1950, "mais de $40 \%$ de toda a produção industrial brasileira e quase $3 / 4$ da produção de bens de capital e consumo duráveis estava concentrada na Grande São Paulo" (NEGRI e PACHECO, 1994). As fábricas construídas neste período tendem a refletir o padrão de fábricas norte-americanas contemporâneas. Mas também mostram o surgimento de novas diretrizes arquitetônicas, voltadas essencialmente às questões de funcionalidade e de praticidade. As plantas tornam-se mais flexíveis e racionalizadas, os sistemas construtivos adotam materiais novos como o concreto armado e o aço, atendendo ao mesmo tempo a um programa complexo e aos novos modos de vida de uma sociedade cujos padrões de vida, trabalho e consumo se modernizavam (FRANCISCO, 2000). O desenvolvimento de muitas destas plantas demandava um número maior de profissionais envolvidos, o que levava as construtoras a frequentemente contratarem um número extra de profissionais para projetos específicos. Nesta época, grande parte dos profissionais, se não a maioria, trabalhavam como autônomos, não constituindo qualquer custo fixo de manutenção de uma estrutura física. Sublocavam salas em escritórios ou em empresas de arquitetura de amigos quando surgiam projetos. Tal prática se completava com a contratação informal de desenhistas de arquitetura, também autônomos - existentes em grande número então -, ou de estagiários. (SENA BATISTA, 2013) Na maior parte dos projetos em que esteve envolvida, Georgia Louise Harris Brown atuou desta forma. Ela não era funcionária contratada de nenhuma construtora dada a sua condição de estrangeira e sem registro profissional. 
Foi neste cenário de expansão industrial e imobiliária, comandado fundamentalmente por homens brancos, que Georgia atuou por mais de duas décadas no desenvolvimento e projeto de grandes plantas industriais. Se sua condição racial e de gênero provavelmente representaram obstáculos à sua promoção e reconhecimento, o fato de provir dos Estados Unidos deve tê-la de algum modo favorecido: afinal tratava-se de um país cujos valores e negócios vinham se afirmando no Brasil de modo incontrastável desde a Segunda Guerra Mundial, e de lá ela trazia uma formação e atuação híbridas, entre a engenharia e a arquitetura, e uma folha corrida que compreendia escritórios e obras de prestígio. Na construtora de Charles Bosworth, ela colaborou no projeto de três indústrias: Fundição de Motores Ford (1957-63), em Osasco; Pravaz Recordati Laboratórios S/A (1960-63) em São Paulo; e Pfizer Corporation do Brasil (1960) em Guarulhos. Na RACZ ela atuou como arquiteta principal, entre 1963 e 1972, e foi responsável pela execução do Parque Industrial da Kodak em São Jose dos Campos (1969-71/1975-76), do escritório da KODAK em São Paulo (sem data) e da indústria de espumas e colchões Trorion S/A (1963-1965), em Diadema.

Em Guarulhos, ela encontraria um processo de rápida industrialização com a construção das rodovias Presidente Dutra e Fernão Dias na década de 1950. O município que até então sediava indústrias de pequeno porte passara a absorver inúmeras plantas industriais, cujas localizações se deram às margens das rodovias (WILHEIM, 1969). Grandes empresas como a Phillips (1958), a Ollivetti (1958), a Asea (1954), a Microlite (1954), a Borlem (1967), muitas vezes projetadas por empresas e arquitetos de renome, assim como a Pfizer e outras ali se instalaram, formando o que viria a ser denominado Parque Industrial de Guarulhos. Segundo Oliveira (2008), em 1953, eram 27 grandes indústrias nele instaladas; em 1956, esse número chegou a 90, além de 80 pequenas fábricas, atraindo também, a partir de então, enorme afluxo migratório para a cidade.

A construção da filial da multinacional farmacêutica Pfizer dentro deste Parque Industrial em 1958 foi o primeiro grande contrato assinado pela Construtora de Bosworth. Com a experiência de projetos anteriores, a proposta partia da ideia da fábrica como um complexo no qual cada função era abrigada em um edifício distinto, interconectando os diversos blocos por meio de caminhos e viadutos. Os prédios ocupam aproximadamente $1 / 10$ de um terreno de $200.000 \mathrm{~m} 2$. Na lateral direita do terreno está o maior bloco do conjunto, que abriga a produção farmacêutica e compreende um depósito de matéria-prima, área central de produção e embalagem dos medicamentos, além de um depósito de produtos finalizados. A construtora ficou encarregada pelo trabalho de construção, assim como pelo projeto, engenharia, elementos hidráulicos e elétricos e até mesmo pela instalação de maquinário e escritórios. Uma grande equipe foi mobilizada, e além de Bosworth atuaram outros arquitetos entre eles Niels E. Headeager e Georgia Brown. (figura 2)

Perto do fim da construção da Pfizer, a escala dos contratos da empresa de Bosworth começava a crescer significativamente e eles foram incumbidos da construção de uma das bem equipadas fundições das indústrias Ford no mundo, o primeiro deste gênero a ser instalado nas Américas, em Osasco (LEFFINGWELL, 2003). Até os anos 1950 a cidade era marcada pela presença de inúmeras cerâmicas e olarias, mas justamente nesse período, como toda a região às margens dos rios Tietê e Pinheiros, da Vila Prudente, Vila Guilherme a Santo Amaro, passando pelo Pari, o Cambuci, a Mooca, observaria um significativo desenvolvimento industrial, justamente impulsionado pela 
Figura 2: Vista aérea do Conjunto Industrial Pifzer em Guarulhos. Fonte: Revista Acrópole n. 266 (1960, p.55).

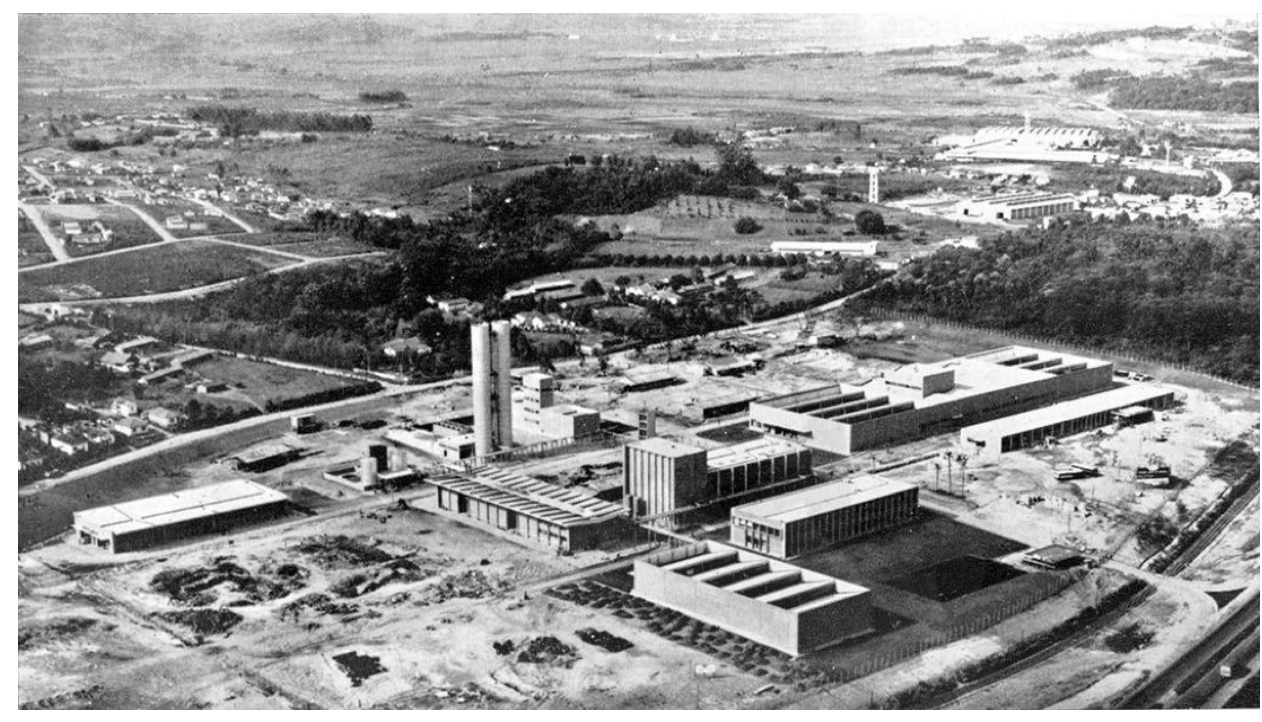

instalação ali de indústrias do setor automotivo, como a Ford e a Braseixos, assim como de material de transporte (Cobrasma), elétricas (Osram, Brown Boveri, Charleroi), mecânicas, metalúrgicas e de materiais de construção, como a Eternit do Brasil, entre outras. (BRITTO, 2010)

O projeto da Fundição de Motores Ford (1957-63) foi encomendado à Construtora no fim dos anos 1950, e novamente contou com a participação de grande número de profissionais. A edificação foi implantada em um terreno do Parque Industrial de Osasco, ocupando todo um quarteirão. Composta por um conjunto de seis prédios - o da fundição, o escritório e restaurante, o vestiário, uma casa de bombas, uma casa de manobra de força e uma portaria - a rusticidade do tijolo aparente no exterior não esconde o emprego de soluções arrojadas, como a cobertura em concreto do galpão principal, iluminada zenitalmente, onde localizadas todas as operações propriamente fabris, as seções de fabricação de modelos, moldagem, fornos elétricos e as linhas de fundição. (figura 3)

A inauguração da Rodovia Presidente Dutra também é tida também como um dos elementos que desencadeou o desenvolvimento de um outro eixo de industrialização ao longo do Vale do Paraíba, até o Rio de Janeiro. Exemplares importantes da arquitetura fabril moderna brasileira ali floresceram das pranchetas de Oscar Niemeyer, os irmãos Roberto, Rino Levi, Giancarlo Palanti, Paulo Antunes Ribeiro etc. Ao longo da rodovia, um grande número de indústrias nacionais e, principalmente, multinacionais perceberam o potencial desta região como lugar de instalações fabris. Foi em suas margens, na altura de São José dos Campos, que em 1969 a KODAK começou o projeto de instalação de um parque industrial. O projeto desenvolvido por Georgia Brown e Aníbal de Almeida Fernandes, ambos arquitetos contratados pela Construtora RACZ. (figura 4) Ainda em obras, a propósito, o projeto foi a ela atribuído pelo arquiteto Paulo Bruna em sua tese de doutorado concluída na FAU-USP em fins de 1972, que nele 
15 BRUNA, Paulo Julio Valentino. Arquitetura, Industrialização e Desenvolvimento. São Paulo: Perspectiva, 1976, p. 142

Figura 3: Vista área da Fundição de Motores Ford em Osasco. Fonte: Revista Acrópole n. 248 (1959 p. 289).

Figura 4: Vista aérea do Parque Industrial da Kodak em São José dos Campos. Fonte: Acervo Departamento de Cultura de São José dos Campos (1984). reconheceu um exemplo típico da adoção de pré-moldados de concreto armado em construções industriais do período. ${ }^{15} \mathrm{O}$ projeto executivo foi elaborado por Georgia, que fez uma readequação do projeto americano da fábrica em Rochester, no estado de Nova lorque. Mas se este era formado por um bloco único, o que Georgia propôs era composto de edifícios separados interconectados por ruas internas. Algo que ela já havia experimentado no projeto anterior para a Pfizer, em Guarulhos. Outros elementos como a utilização de tijolos aparentes em todas as fachadas, e brises de concreto também podem ser verificados em empreendimentos industriais anteriores. Este foi certamente o projeto mais importante da trajetória da arquiteta, reconhecidamente sua principal responsável, em contraste com projetos deste porte nos quais atuara como colaboradora frequentemente anônima.
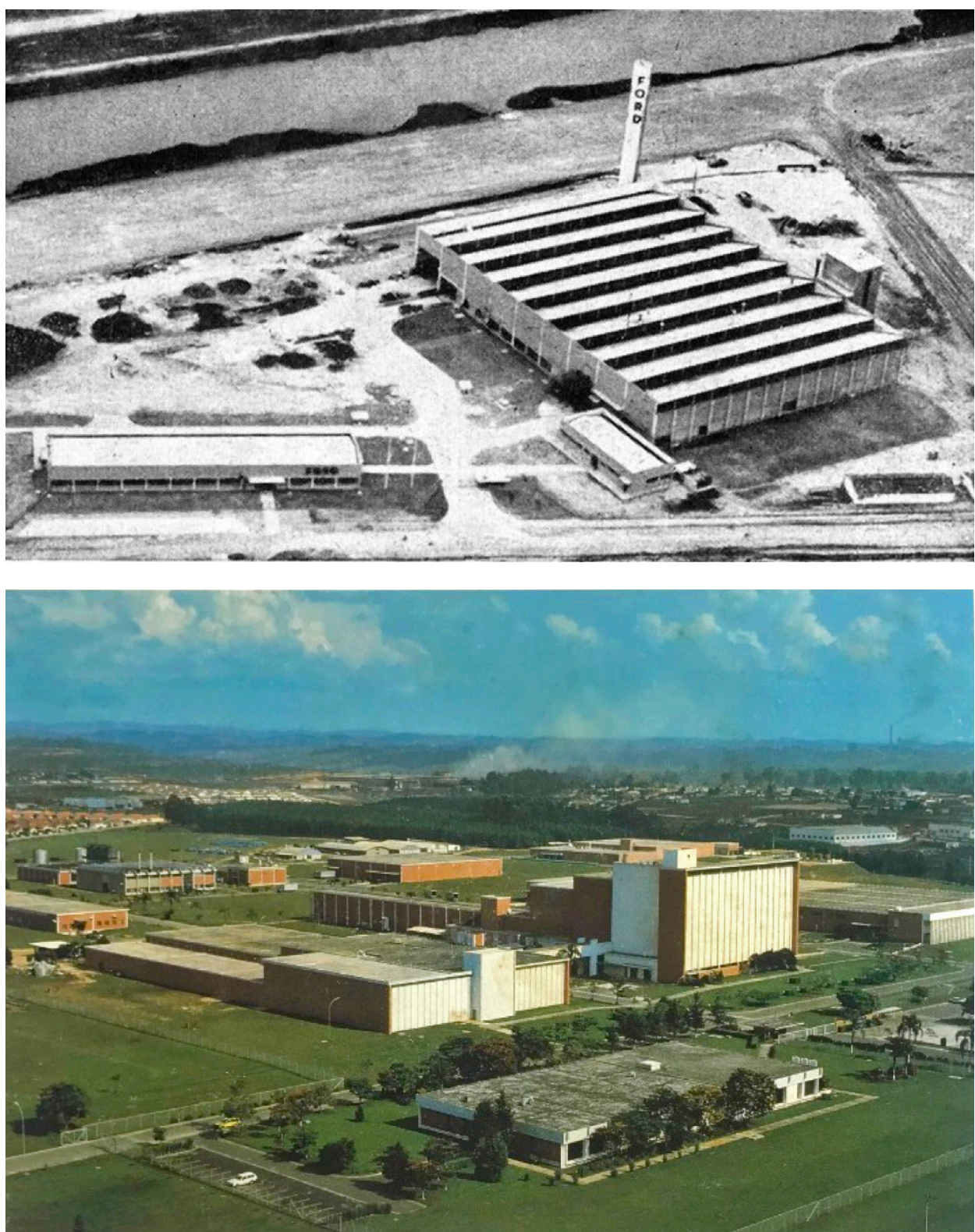
O porte dessas indústrias revela a dimensão da ocupação do território metropolitano por esses grandes empreendimentos naquele momento: a Pfizer Corporation do Brasil instalara-se em uma área de 28.000 m2, a Ford Motors ocuparia uma quadra inteira, a Pravaz Recordati chegaria a 185.000 m2, e a Kodak a 35.000 m2. O desenvolvimento industrial ao longo das autoestradas definiam uma nova paisagem suburbana, caracterizada pelo grande porte e a dispersão das edificações fabris em grandes glebas, que de resto permitiam-Ihes ampliações de vulto. Ainda que produzindo efeitos locacionais comparáveis aos dos antigos "subúrbios-estação", como bem observou Languenbuch em sua tese de doutorado de 1968, a nova malha regional de rodovias permitiam uma expansão industrial sem precedentes, muito além das margens ferroviárias há muito estranguladas pela marcha do adensamento e da valorização imobiliária na cidade (LANGUENBUCH, 1971). Não restam dúvidas do enorme impacto que essas fábricas exerceram sobre as cidades e regiões onde se implantaram, intensificando os processos de incorporação horizontal e urbanização extensiva que provocaria profundas alterações em suas estruturas. (ROMANELLI e ABIKO, 2011)

No decorrer da década de 1960, período de intensificação das plantas industriais em Guarulhos, por exemplo, o crescimento demográfico acompanhava o ritmo da industrialização sem jamais ser complementado pelas necessárias políticas urbanas e habitacionais (GAMA, 2010). O modelo reproduziu-se em outras direções: rumo ao ABC pela Via Anchieta, e a Campinas pela Anhanguera, ao fim e ao cabo determinando o perfil hegemônico de expansão territorial da grande São Paulo por várias décadas. Ao conjugar industrialização e metropolização, o crescente adensamento produtivo e populacional que se desenvolveu ao seu redor redefiniria a questão urbana no país: doravante marcada pela exigência de grandes planos territoriais e regionais, pela construção de vias expressas, por uma modernização na forma de enclaves, pela escassez de moradia popular tal o gigantesco deslocamento demográfico que ele produziu, inclusive de trabalhadores da indústria fordista, para as margens da aglomeração paulistana.

Se aqui ou ali, a arquiteta viria a desempenhar um papel de maior ou menor relevância nesse processo de avanço das fronteiras metropolitanas de São Paulo, a dimensão de suas responsabilidades parece ter se equilibrado entre ao menos três circunstâncias de existência a ela inescapáveis: a condição de mulher, ademais divorciada, de todo desfavorável nesse mundo viril da indústria em desenvolvimento; a origem étnica ambivalente em um país no qual profissionais de nível superior e seus contratantes poderiam abstraí-la ou amortecê-la conforme o caso; e o status de cidadã norte-americana que, além do capital simbólico e do pleno domínio da língua inglesa, poderia eventualmente beneficiar-lhe, tal a expansão ilimitada dos interesses econômicos dos EUA no país.

\section{Histórias de fantasmas na cidade grande}

Fantasmas são misteriosos, enigmáticos, perigosos. Eles podem aparecer e desaparecer sem avisar nem deixar rastros; são tão efêmeros, quanto imortais, pois que já mortos e ao mesmo tempo prestes a ressurgir a qualquer momento, em circunstâncias e figurações variadas, com conteúdos variados, condensando energias físicas e anímicas em imagens-símbolo, que se perpetuam no tempo como qualquer outro objeto material ou modo de pensar. Em seu prefácio à coletânea de Aby Warburg, Histórias de 
16 DIDI-HUBERMAN, Georges. As formas sobrevivem: a história se abre. In A Imagem Sobrevivente. Rio de Janeiro: Contraponto, 2013, p. 35.

17 Idem, p. 13

18 A pesquisa feita sobre sua trajetória mostrou que ela foi tema de algumas matérias em revistas e jornais dos EUA. Cf. NEGRO DIGEST 08, VOLUME 2, 1950; EBONY MAGAZINE 06, 1950; EBONY MAGAZINE 56, 1954; The Pittsburgh Courier , 3 de Dez 1949.

19 Brown e Domingues LTDA (1963) - sócios: Louise Brown e Jaulino Rodrigues; GRYPHUS Arquitetura s/c LTDA (1975) sócios: Louise Brown e Helena Mendes Rotundo; GRYPHUS Arquitetura s/c LTDA (1977) sócios: Louise Brown e Aníbal de Almeida Fernandes; GRYPHUS Arquitetura s/c LTDA (1980) sócios: Louise Brown e Daniel Raymond Michel Longbloed; Brown Bottene Construtora (1990) - sócios: Louise Brown, Neyde Bottene Camacho, Antônio Sérgio Camacho e Izabel Cristina Magalhães.

20 Louise consegue a licença profissional no CREA em 1970. Ver processo R1274/69 CAU/SP.

21 Diário Oficial do Estado de S. Paulo, 13 de Outubro de 1979. fantasma para gente grande, Leopoldo Waizbort assim resumiu a noção de Nachleben no trabalho do autor alemão: "Morta-viva. Sua presença revela-se por vezes de modo evidente, mas os sentidos são frequentemente intrincados e alusivos, e são sempre transformados. Dar conta dessas modalidades de presença e transformação, que rompem com uma temporalidade linear e dão vazão ao múltiplo e heterogêneo", é o desafio historiográfico por ele proposto (WAIZBORT, 2010:6). É claro que a questão posta por Warburg remete-se especificamente à história da arte, ou seja, ao exame das imagens segundo um método científico, como coisas já mortas, definitivamente perdidas, pertencentes ao passado. Mas para ele, o que importava era compreender as sobrevivências, reaparições e transformações das imagens de época para época, de um lugar para outro, atravessando fronteiras entre disciplinas, teorias, objetos, de modo a regenerar sua vivacidade histórico-cultural, seu tempo de fantasma: "fantasmas cujos traços mal são visíveis, porém se disseminam por toda parte: num horóscopo da data de nascimento, numa carta comercial, numa guirlanda de flores (justamente aquela de que Guirlandaio tirou seu apelido), no detalhe de uma moda do vestuário, uma fivela de cinto, uma circunvolução particular de um coque feminino..." 16

Detalhes aparentemente banais também poderiam ser capazes de dar sentido, de produzir sintomas, marcos, rastros para o historiador. Sobretudo quando diante de presenças sutis, discretas, vagas. Como elas aparecem e desaparecem na história? Em que figura, que roupagem? Com que detalhes, especificidades, singularidades, passíveis de serem filologicamente autenticados? Ou antes, como as questões que sua presença hoje suscita relacionam-se com problemas já formulados, resolvidos ou não? Que superstições, isto é, que persistências de outras eras, que ressonâncias, que modos de ver, de pensar, de estranhar, que preconceitos elas ativam? Que vínculos enigmáticos, obscuros, que misturas entre coisas passadas e presentes, que rumores de coisas mortas elas ecoam? Que assombrações, que populações de fantasmas as habitam? Afinal - refraseando Didi-Huberman - nenhum fantasma jamais nasce; ele sempre recomeça; mais ou menos como a narrativa histórica. ${ }^{17}$

Apesar de sua vasta contribuição e atuação no mercado arquitetônico brasileiro, e de sua formação e experiência em importantes escritórios dos EUA, a figura de Georgia é um caso típico destas fantasmagorias historiográficas. Sem dúvida porque embaçada, subestimada em sua época, seja nas grandes empresas em que atuou, seja no sistema de acreditação profissional, seja em livros, revistas, jornais, assim como nos estudos acadêmicos mais recentes, sua atuação permanece misteriosa, espectral. ${ }^{18}$ De fato, entre suas poucas aparições na imprensa, por diversas vezes Georgia comparece no Diário Oficial do Estado de São Paulo. Em sua maioria referindo-se às múltiplas empresas ${ }^{19}$ que ela integrou ao longo de uma vida profissional de difícil estabelecimento. ${ }^{20} \mathrm{Em}$ uma delas, contudo, um outro fato, aparentemente irrelevante vem à tona: ficamos sabendo que Georgia foi vítima de um furto na rua Augusta em uma tarde de 1979, e que na bolsa subtraída havia "a importância de $\mathrm{Cr} \$ 1.600,00$ em dinheiro, uma calculadora, carteiras, cigarros, bússola, régua, canetas, lapiseiras, piteira, porta batom, óculos e chaves avaliados em $\mathrm{Cr} \$ 4.000,00 " .{ }^{21}$ De uma hora para outra, esse personagem fugidio parece ser descrito em pormenor: andava a pé pela rua Augusta, usava piteira, carregava óculos e batom em sua bolsa ao lado dos instrumentos de trabalho, como tantas mulheres de classe média urbana, profissionalizada, móvel, independente nos anos 1970. A descrição policial não deixa de ser trivial; mencionada pelo nome e por meio dos objetos pessoais furtados, não parece dizer muito a seu respeito; trata-se de 
um indivíduo qualquer, indistinto, sem biografia, e apenas por um instante flagrado no registro oficial como uma mulher comum. Mas a fantasmagoria é aqui ainda mais relevante porque não é apenas em torno deste ou daquele indivíduo que ela se impõe; ou antes, porque o trivial na existência, e o próprio anonimato de uma arquiteta negra e estrangeira, é algo bem mais representativo do que se imagina.

Não por acaso, em O queijo e os vermes, Carlo Ginzburg reconheceu a necessidade de desafiar a grande tradição historiográfica - dos grandes fatos, feitos e dos grandes homens do passado - trazendo à tona a vida de Menocchio, esse moleiro friulano queimado no século XVI por ordem do Santo Ofício depois de uma vida transcorrida no anonimato: "Não é um objetivo de pouca importância estender às classes mais baixas o conceito histórico de indivíduo (...). Alguns estudos biográficos mostraram que um indivíduo medíocre, destituído de interesse por si mesmo - e justamente por isso representativo - pode ser pesquisado como se fosse um microcosmo de um estrato social inteiro num determinado período histórico" (GINZBURG, 1998: 2627). Geórgia não era por certo um membro das classes baixas, nem sua produção profissional revela-se destituída de interesse nela mesma. Mas o que a passagem de Ginzburg revela é justamente a ultrapassagem da existência individual no trabalho da fantasmagoria. Seus mistérios, lacunas, silêncios, ainda que tratados na microescala de uma vida, podem ser encarados como parte da narrativa a seu respeito, como traços representativos, passíveis inclusive de serem assumidos nas dúvidas, incertezas, hesitações e hipóteses que suscitam. (GINZBURG, 2007: 263-265)

Remetendo-se, pois, não somente ao indivíduo, mas a seu pertencimento social, ao universo de circunstâncias sociais que o atravessam, que distinguem ou amortecem a sua presença, a fantasmagoria revela-se uma categoria metodologicamente válida. Que questões, afinal, uma figura como Georgia, como tantos outros arquitetos negros, mulheres ou estrangeiros, nos desafiaria a responder? O que era ser uma arquiteta anônima em uma cidade brasileira em vias de metropolização, onde o mercado de vocações e talentos tornava-se mais e mais competitivo? O que era viver e trabalhar na construção dessa cidade tão peculiar que era São Paulo, ao mesmo tempo um emblema da modernização do país, de passagem do rural ao urbano-industrial e do escravo ao cidadão, e, como à época já mostrava o sociólogo pardo Florestan Fernandes, não lograra constituir-se um substrato material verdadeiramente urbano nem romper com a ilusão de que a vida nela se dava em condições similares a de grandes metrópoles de países democráticos, industrializados, majoritariamente brancos? (FERNANDES, 1960) O que significava ser uma arquiteta anônima e negra trabalhando nessas frentes de vanguarda do desenvolvimento e circulando em um universo eminentemente branco e masculino de arquitetos, engenheiros, executivos, construtores e operários da construção civil? O que era ser ora vista como negra, ora como branca; e como estrangeira, ora como estadunidense, ora como afroamericana, esse tipo de apátrida em sua própria terra, como desde aqueles anos vêm nos mostrando alguns dos mais penetrantes intelectuais negros do mundo, como James Baldwin, Angela Davis, Tony Morrison ou Achile Mbembe? Que questões poderiam, ou valeriam à pena ser enunciadas à luz de sua existência, e de seu trabalho? De que forma, segundo que critérios, que problemáticas, com que propósitos?

Os historiadores do urbanismo e da arquitetura no Brasil não apenas precisariam avançar no conhecimento destes personagens, cujo apagamento e aparição não cessam de revelar 
22 Que arquitetos e arquitetas entre as dezenas de profissionais, intelectuais, escritores, artistas, figuras renomadas ou cidadãos anônimos negros, a exemplo de Teodoro Sampaio (1855-1937), Antônio Rebouças (1839-1874), André Rebouças (1838-1898), Enedina Alves Marques (19131981), Machado de Assis, Lima Barreto, Mário de Andrade, Carolinade Jesus, Maria Firmina dos Reis, Abdias do Nascimento, Arthur Timóteo da Costa e Maria Auxiliadora. o funcionamento de fantasmas na sociedade, na disciplina e na profissão. ${ }^{22}$ Senão como uma forma de retratação histórica, ao menos como reparação de lesões e cicatrizes infligidos "àqueles e àquelas que passaram por processos de abstração e coisificação na história"; como restituição das "partes que [Ihes] foram amputadas, para a reparação de laços que foram quebrados", de forma a reinstaurar "o jogo da reciprocidade, sem o qual não se pode atingir a humanidade". (MBEMBE, 2018: 304-305)

Sem desconsiderar o trabalho empírico, seria proveitoso às pesquisas de campo, às monografias individuais ou aos estudos de casos não mais se aterem a discursos feitos anteriormente, nem muito menos à pretensão de encontrar novos grandes mestres, heróis ou heroínas, dignos de biografias. Talvez fosse mais promissor investir na produção de estratégias capazes não só de expandir ou refutar os cânones, mas de apanhar os múltiplos modos de funcionamento de práticas não canônicas, aliás não menos representativas ou impactantes, na verdade, quase sempre responsáveis pela produção da maior parte de nossas cidades. Práticas de colaboradores, especializados ou não no interior de empresas, escritórios, órgãos públicos, agências internacionais; ou de figuras que atuaram isoladamente, em parcerias, sob contratos precários, na maior parte das vezes de modo fragmentário, subalterno, anônimo. Como nos lembra, Gwendolyn Wright, nessa direção talvez pudéssemos compreender os próprios sistemas de poder na base de nossas instituições, incluindo-se aí não somente os sistemas de canonização, seus mitos e protagonistas, mas também as formas institucionais do sexismo, do racismo, do chauvinismo, da xenofobia, do colonialismo, do corporativismo, nas quais se ancoram muitas das hierarquias pessoais e estruturais que rondam o sistema da arquitetura e do urbanismo (WRIGHT, 2009). Afrontar essas e outras fantasmagorias históricas, recuperar trajetórias individuais mais ou menos anônimas, e estruturar seus campos sociais e institucionais de entendimento são caminhos que poderiam permitir a incorporação desta agenda de revisões, reparações e desvios na historiografia da cidade e do urbanismo.

Há riscos inevitáveis na recuperação da história e da memória de episódios e personagens muito distantes de nós temporalmente. Basta recordarmos uma das mais belas cenas de Roma, de Fellini, quando durante uma obra nos subterrâneos da cidade uma broca acidentalmente perfura uma parede que dá acesso a uma câmara desconhecida. Nela, afrescos antigos, dissolvem-se ao entrarem em contato com o ar exterior. Estas imagens, guardadas durante séculos, esquecidas antes de desaparecerem, existiam como imagens de um arquivo incerto, enigmático, sem catalogação. O trabalho do historiador tem algo a ver com esse de encontrar imagens, formas, objetos, espaços, corpos, saberes, práticas, indivíduos, em sua presença e transformação, em seus silêncios e modos de expressão, em seus vestígios e resíduos no limiar do desaparecimento. Há implícito nesta tarefa, um cuidado maior: ao reavivar estes fantasmas, muitos deles estarão de tal modo silenciados que será necessário também fazer silêncio para se ouvir os seus mínimos ruídos, reconhecendo as suas especificidades históricas, antropológicas, geográficas, metodológicas.

\section{Referências bibliográficas}

BRUNA, P. J. V. Arquitetura, Industrialização e Desenvolvimento. São Paulo: Perspectiva, 1976. 
CUNHA, M. C. da. Da senzala ao sobrado: arquitetura brasileira na Nigéria e na República do Benim. São Paulo, Nobel/Edusp, 1985.

BRITO, C. R. de. Contribuição ao estudo do poder local em Osasco: um estudo geográfico-político. Tese de Doutorado em Geografia. FFLCH-USP, São Paulo, 2010.

CANO, W. Desconcentração produtiva regional do Brasil 1970-2005. São Paulo: Ed. Unesp, 2008.

COLOMINA, B. "With, or Without You: The Ghosts of Modern Architecture." In: BUTLER, Cornelia; SCHWARTZ, Alexandra (orgs.). Modern Women: Women Artists at The Museum of Modern Art. New York: Museum of Modern Art, 2010, p. 217-231.

COSTA, L. "Depoimento de um arquiteto carioca". In: Centro dos Estudantes Universitários de Arquitetura. Lúcio Costa: sobre arquitetura. Porto Alegre: UFRGS, 1962;

DIDI-HUBERMAN, G. Sobrevivência dos vaga-lumes, Belo Horizonte: Editora UFMG, 2011.

A Imagem Sobrevivente: história da arte e tempo dos fantasmas segundo Aby Warburg. Rio de Janeiro: Contraponto, 2013.

FERNANDES, F.; BASTIDE, R. Relações sociais entre negros e brancos em São Paulo. São Paulo: UNESCO/Anhembi, 1955.

FERNANDES, F. Negros e brancos em São Paulo. São Paulo: Cia. Editora Nacional, 1959. A integração do negro na sociedade de classes. São Paulo: Cia Editora Nacional, 1965; O Homem e a cidade-metrópole. In: Mudanças Sociais no Brasil. São Paulo: Difusão Europeia do Livro, 1960, p. 266-283.

FRANCISCO, A.M. Edifício Fabril e Espaço Metropolitano: São Paulo, anos 50. Dissertação de Mestrado em Arquitetura e Urbanismo. EESC-USP, São Carlos, 2000.

GAMA, N. C. de O. O processo de conformação da periferia urbana no município de Guarulhos: os loteamentos periféricos como (re)produção de novas espacialidades e lugar de reprodução da força de trabalho. Dissertação de Mestrado em Geografia Humana. FFLCH-USP, São Paulo, 2010.

GINZBURG, C. O queijo e os vermes: o cotidiano e as ideias de um moleiro perseguido pela Inquisição. São Paulo: Companhia das Letras, 1998.

"Micro-história: duas ou três coisas que sei a respeito" , In: O fio e os rastros: verdadeiro, falso, fictício. São Paulo: Companhia das Letras, 2007, p. 249-279.

LAGE, R. R. A Construção Pesada Brasileira. Tese de Doutorado. FFLCH-USP, São Paulo, 2017.

LANGENBUCH, J.R. A Estruturação da Grande São Paulo: estudo de geografia urbana. Rio de Janeiro: IBGE, 1971.

LEFFINGWELL, E. Construindo São Paulo: Um Pioneiro da Arquitetura no Brasil, 2003 (inédito).

MBEMBE, A. Crítica da Razão Negra. São Paulo: n-1 edições, 2018.

MELLO, J. O arquiteto e a produção da cidade: a experiência de Jacques Pilon, 1930-1960. São Paulo: Annablume/ Fapesp, 2012;

MEMÓRIA FOTOGRÁFICA de São José dos Campos, 1916-1952. Prefeitura Municipal, Departamento de Cultura, 1984.

NEGRI, B; PACHECO, C. "Mudança tecnológica e desenvolvimento regional nos anos 90: a nova dimensão espacial da indústria paulista". Espaço \& Debates, Ano XIV, n 38, p. 62-82, 1994.

PEEREN, E. The Spectral Metaphor. Living Ghosts and the Agency of Invisibility. Londres/Nova York: Palgrave Macmillan, 2014. 
RIBEIRO, D. O povo brasileiro: a formação e o sentido do Brasil. São Paulo: Companhia das Letras, 1995.

ROMANELLI, C.; ABIKO, A. K. Processo de Metropolização no Brasil. Texto Técnico da Escola Politécnica da USP. Departamento de Engenharia de Construção Civil. São Paulo: EPUSP, 2011.

SENA BATISTA, A. J. de. Os Irmãos Roberto: por uma arquitetura constituída de padronização e singularidade. Dissertação de Mestrado em História. PUC-Rio, Rio de Janeiro, 2006.

SOLOMON-GODEAU, A. Provocação e fantasmagoria: táticas críticas em um modo "menor". In Histórias das Mulheres, Histórias Feministas: Antologia. São Paulo: MASP, 2019, p. 284-300.

WAIZBORT, L. Apresentação. In: WARBURG, Aby. Histórias de fantasma para gente grande. São Paulo: Companhia das Letras, 2010, p. 4-16.

WASHINGTON, R. Georgia Louise Harris Brown. In: African American Architects: A Biographical Dictionary, 1965-1945, ed. Dreck Spurlock Wilson. New York: Routledge, 2004, p 100-104.

WILSON, D. S. (org.). African American Architects: A Biographical Dictionary, 1965-1945. New York: Routledge, 2004.

WRIGHT, G. Women in Modernisn. In: Women in Modernism: Making Places in Architecture. Colóquio.MOMA, 2007.

WILHEIM, J. Plano de Desenvo/vimento de Guarulhos - PUG. Prefeitura de Guarulhos, 1969. 